\title{
Differences in virulence of Sporothrix schenckii conidia related to culture conditions and cell-wall components
}

\author{
KARLA S. S. FERNANDES, HERBERT L. MATHEWS* and LEILA M. LOPES BEZERRA \\ Department of Cell Biology and Genetics, Biology Institute, University of the State of Rio de Janeiro, Rio de \\ Janeiro, Brazil and *Department of Microbiology and Immunology, Loyola University of Chicago, Maywood, IL, \\ USA
}

\begin{abstract}
A murine model was used to evaluate the virulence of Sporothrix schenckii conidia cultured for 4, 7, 10 or 12 days in Sabouraud's dextrose broth (SDB). A correlation was observed between length of culture and virulence. Mice infected intravenously with $S$. schenckii conidia cultured for 4 or 7 days showed $40-100 \%$ cumulative mortality. In contrast, mice infected with conidia from cultures grown for 10 or 12 days in SDB showed no mortality (100\% survival). A much greater accumulation of fungal colony forming units (cfu) was observed in the lungs, livers and spleens of mice inoculated with conidia of $\boldsymbol{S}$. schenckii cultured for 7 days than in mice infected with conidia cultured for 12 days. The livers of mice from the former group showed a widespread granulomatous reaction whereas mice inoculated with $S$. schenckii cultured for 12 days showed a more limited response with fewer granulomas. No difference in viability or replicative capacity was discerned for these $S$. schenckii cultured cells. However, the more virulent forms of the fungus showed differences in cell-wall sugar composition with rhamnose:mannose molar ratios of 1.7:1.0 for cells cultured for 4 days and 1.0:1.7 for conidia cultured for 12 days. These results suggest that the virulence of $S$. schenckii conidia may be determined by their cell-wall composition.
\end{abstract}

\section{Introduction}

Sporothrix schenckii is a pathogenic dimorphic fungus that produces various forms of clinical disease. Sporotrichosis can be subacute or chronic, cutaneous or subcutaneous, and is often associated with lymphangitis or lymph node enlargement [1]. Systemic forms of the disease have been reported, especially in immunocompromised individuals [2-5]; these are thought to be a consequence of inhalation of conidia [3] or dissemination from a cutaneous or subcutaneous lesion [2]. The underlying basis for the various clinical forms of sporotrichosis is not fully understood. The clinical forms have been attributed to: the size of the initial fungal inoculum, the nature of the host's immune response, the virulence of the infecting fungal isolate, the depth of traumatic inoculation and the thermal tolerance of the fungus (growth capacity at $35^{\circ} \mathrm{C}$ or

Received 24 Oct. 1997; revised version accepted 21 June 1998.

Corresponding author: Dr L. M. Lopes Bezerra (e-mail: leila@uerj.br). $\left.37^{\circ} \mathrm{C}\right)[6-10]$. More than one of these factors may contribute to the development of sporotrichosis.

The outer cell wall of $S$. schenckii comprises a thick, electron-dense microfibrillar material [11] and the host response to peptido-polysaccharide antigens of the fungal surface is thought to contribute to immunity [12]. Peptido-rhamnomannan is the major component of the outer cell wall that elicits delayed-type hypersensitivity reactions as well as antibody responses $[12,13]$. The antibody responses have been investigated in detail and the main immunogens are related to $\mathrm{N}$ - and O-glycosidically linked chains present in the mycelial and yeast phases $[12,14]$. The O-linked oligosaccharides vary in size from a dito a pentasaccharide that has subterminal $\alpha$-Dglucopyranosyluronic acid units mono- and di-substituted by $\alpha$-L-rhamnosyl non-reducing end units [15]. The rhamnose non-reducing end units of the O-linked oligosaccharides are the main antigenic epitopes described for this fungus [14].

Whether or not cell-wall peptido-polysaccharides of $S$. 
schenckii may influence the course of sporotrichosis is not fully understood. In this study, the influence of cell-wall sugar composition on the development of experimental sporotrichosis was assessed.

\section{Materials and methods}

Animals

Male BALB/c and Swiss mice were obtained from Fundação Oswaldo Cruz (FIOCRUZ, Rio de Janeiro, Brazil) and used at 6-8 weeks of age. The animals were supplied with sterilised food and water ad libitum throughout the period of study. Groups of 10 mice, either BALB/c or Swiss strains, were used for the mortality experiments; each experiment was repeated at least three times. The data represent the cumulative survival times for each group until the 45 th day after infection.

\section{Fungus and infection}

S. schenckii strain 1099-18 was used throughout the study. It was obtained originally from the Mycology Section of the Department of Dermatology, Columbia University, New York, USA and was maintained on Sabouraud's dextrose agar (SDA) slants at $4^{\circ} \mathrm{C}$. On day 0 of culture, a slice of the plate culture was inoculated into Sabouraud's dextrose broth (SDB). The mycelium phase of $S$. schenckii was grown at $25^{\circ} \mathrm{C}$ for $4,7,10$ or 12 days on a rotary shaker at $150 \mathrm{rpm}$. Conidia were collected at $4,7,10$ or 12 days, separated by gauze filtration and washed with sterile $0.05 \mathrm{M}$ phosphatebuffer saline (PBS), pH 7.2. The conidia were counted with a Neubauer chamber and viability was ascertained as cfu after incubation for 6 days on Brain Heart Infusion (BHI; Oxoid) Agar at $37^{\circ} \mathrm{C}$. Conidia were designated as $S s-4, S s-7, S s-10$ and $S s-12$, corresponding to the days maintained in culture before harvest. After ether anaesthesia, each mouse was inoculated intravenously (i.v.) in the orbital eye vein, with $5 \times 10^{6}$ conidia in $0.2 \mathrm{ml}$ of sterile PBS. Mice were manually restrained and the bevelled edge of a 27-gauge needle attached to a tuberculin syringe was inserted into the orbital eye vein. This was accomplished by slow axial rotation of the syringe advancing the bevelled edge of the needle gently towards the rear of the eye socket until the needle was inserted into the vein. Localisation of the needle was determined by venous return into the hub of the needle.

\section{Determination of the splenic index}

Splenomegaly was determined by the spleen and body weight ratios of mice inoculated with $S s-7$ or $S s-12$, as well as control mice. The relative increase for Swiss or BALB/c mice was determined with the mean value for the control group of each strain equal to one unit.

\section{Determination of $c f u$}

The number of viable micro-organisms in the lungs, livers and spleens of animals infected with $\mathrm{Ss}-7$ and $\mathrm{Ss}$ 12 was determined by cfu counts. At days 14 and 21 after inoculation, three-to-five animals from each strain were killed and the organs were removed aseptically, weighed and homogenised in sterile PBS with a Potter piston. The suspension was adjusted to $10 \mathrm{mg}$ of tissue $/ \mathrm{ml}$. Samples $(100 \mu \mathrm{l})$ of each homogenate were plated on $\mathrm{BHI}$ agar containing penicillin $(10000 \mathrm{U} / \mathrm{ml})$ and streptomycin $(10 \mathrm{mg} / \mathrm{ml})$ (Sigma). The plates were incubated at $37^{\circ} \mathrm{C}$ for 7 days and the number of colonies was counted and expressed as the number of viable $S$. schenckii/g of tissue. Dilutions were made in sterile PBS when necessary.

\section{Statistical analysis}

Values were reported as mean and SD. The unpaired Student's $t$ test and the Wilcoxon rank sum test were used to compare differences between groups; $p<0.05$ was considered significant. The $95 \%$ confidence intervals were calculated for the cfu analysis.

\section{Histopathology}

Samples of livers from animals infected with $\mathrm{Ss}-7$ and $S s-12$ were fixed with buffered formalin $10 \%$, mounted in paraffin, sectioned and stained with haematoxylin and $\operatorname{eosin}(\mathrm{H}$ and $\mathrm{E})$.

\section{Agglutination tests}

$\mathrm{BALB} / \mathrm{c}$ mice were inoculated with a lower inoculum of $S$. schenckii $\left(1 \times 10^{5}\right.$ conidia), as described above. Groups of five animals were bled at regular intervals throughout the 42 days after infection. S. schenckii agglutinating antibodies were estimated by serial dilution of sera from mice infected with either $\mathrm{Ss}_{-} 7$ or $S s-12$, in 96-well, round-bottomed plates. A unit volume $(25 \mu \mathrm{l})$ of a suspension of $S s-7$ or $S s-12$ conidia $\left(10^{8} / \mathrm{ml}\right)$ was added to each well. The plates were incubated for $2 \mathrm{~h}$ at $37^{\circ} \mathrm{C}$ and the maximum dilution that gave a positive agglutination reaction was determined.

\section{Preparation of $S$. schenckii cell wall crude extracts}

The mycelium phase of $S$. schenckii was cultivated in 1-L volumes of SDB in 3-L Erlenmeyer flasks for 4, 7, 10 and 12 days. Cell masses of $S s-4, S s-7, S s-10$ and Ss-12 conidia were separated from hyphae by gauze filtration from a total of $4 \mathrm{~L}$ of culture. Briefly, each cell mass of conidia was suspended in $0.02 \mathrm{M}$ citrate buffer, $\mathrm{pH} 7.0$, and autoclaved for $90 \mathrm{~min}$ at $120^{\circ} \mathrm{C}$. The supernate were separated by centrifugation, dialysed exhaustively against distilled water, precipitated in cold ethanol and lyophilised as described previously [16]. 


\section{Analytical determinations}

The sugar composition of cell-wall fractions from $S$. schenckii conidia was determined as described previously [15]. Analysis was done twice for samples of the crude cell-wall extracts from $S s-4, S s-7, S s-10$ and Ss-12. Each sample, after methanolysis with $0.5 \mathrm{M}$ methanolic $\mathrm{HCl}$ at $80^{\circ} \mathrm{C}$ for $18 \mathrm{~h}$, was trimethylsilylated with bis (trimethylsilyl) trifluoroacetamide-pyridine $(1: 1 \mathrm{v}: \mathrm{v})$ for $4 \mathrm{~h}$ at room temperature and the products were analysed by gas-liquid chromatography (GLC) with a DB-1 capillary column $(30 \mathrm{~m} \times 0.25 \mathrm{~mm})$ at $180-240^{\circ} \mathrm{C}\left(2^{\circ} \mathrm{C} / \mathrm{min}\right.$, then hold $)$. Rhamnose, ribose, mannose, glucose and galactose standards were also derivatised. The monosaccharides in the samples were identified by their relative retention times based on the chromatographic profile of the standards. The molar ratios were determined by the integration of each peak area where the unity corresponded to the smallest area.

\section{Results}

\section{Mortality rates}

The cumulative survival times of mice inoculated with $S s-4$ and $S s-7$ were less than those of mice inoculated with $S s-10$ or $S s-12$ (Fig. 1). BALB/c mice were more susceptible to $S$. schenckii infection than Swiss mice. The relative susceptibility difference by day of death between BALB/c and Swiss strains infected with $S s-7$ was significant $(\mathrm{p}<0.05$, Wilcoxon rank sum test). Differences in mortality rates among groups was not caused by differences in the viability of the inoculum; all spores were $95-100 \%$ viable.

\section{Development of the disease}

The progression of the disease in BALB/c and Swiss mice inoculated with $S s-7$ and $S s-12$ was monitored by viable counts in the lungs, livers and spleens, 14 and 21 days after inoculation. The number of cfu in the lungs was higher for Ss-7-infected animals than for the $S s-12$ group. As shown in Fig. 2, the cfu counts in the livers and spleens of BALB/c mice infected with $S s-7$, 14 days after injection, were two-to-three $\log _{10}$ units higher than the cfu values for Swiss mice. For BALB/c mice inoculated with $S s-12$ conidia, a significant decrease in the number of cfu 21 days after infection was observed (Fig. 2). For the Swiss mice inoculated with either $S s-7$ or $S s-12$ conidia, a decrease in the cfu counts was observed 21 days after infection (Fig. 2). It was not possible to determine the cfu counts for BALB/c mice inoculated with $S s-7$ conidia 21 days after inoculation because of the high mortality rate observed for this group. Fig. 3 shows a comparison between the virulence of $S s-7$ and $S s-12$ determined by cfu counts in the lungs for Swiss mice 14 days after infection. Significant differences $(p<0.05)$ in $c f u$ counts were found between the $S s-7-$ and $S s-12-$ inoculated groups (Figs. 2 and 3), regardless of the mouse strain.

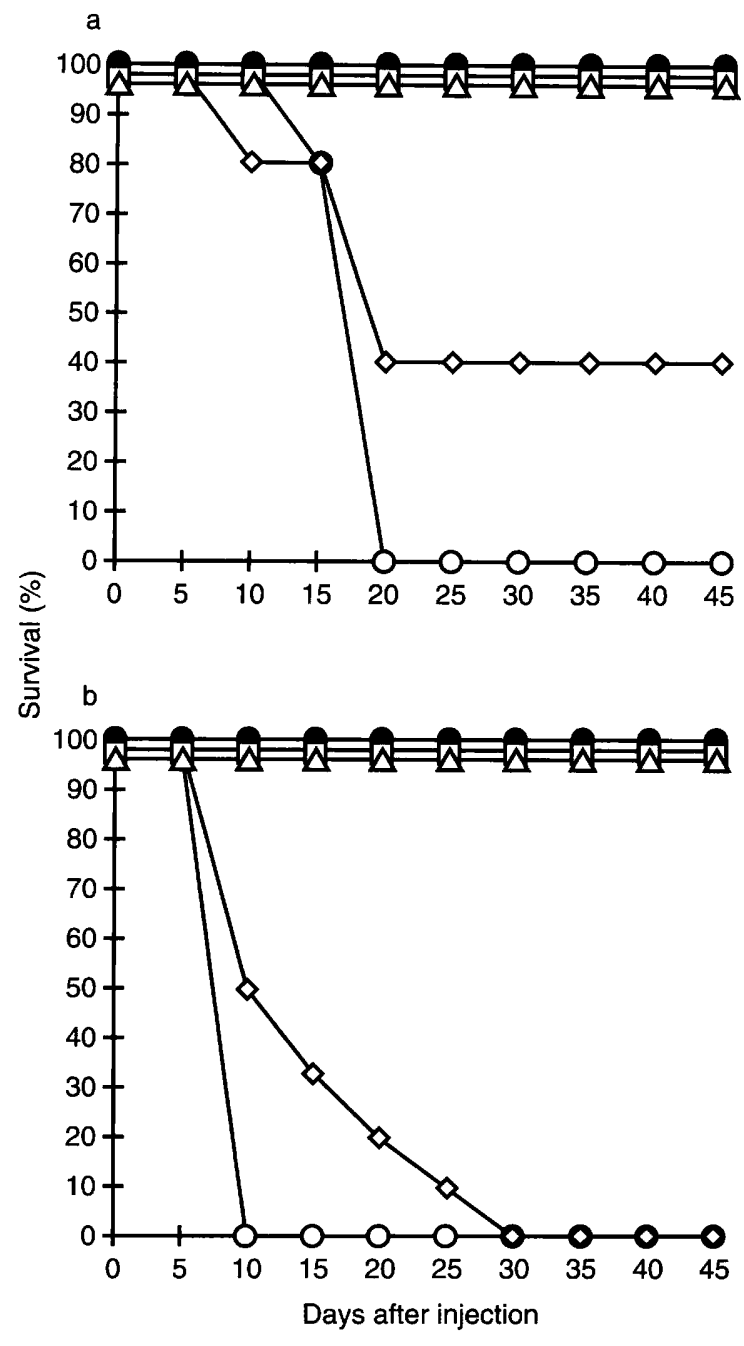

Fig. 1. Survival of (a) Swiss and (b) BALB/c mice $(\mathrm{n}=20)$ after i.v. injection of $5 \times 10^{6} \quad S$. schenckii conidia. The conidia were cultivated in SDB and isolated after 4, 7, 10 or 12 days. Control animals were inoculated with PBS. $O, S s-4 ; \diamond, S s-7 ; \triangle, S s-10 ; \square$, Ss-12; •, control.

\section{Histopathology}

Animals were inoculated i.v. with $S$. schenckii conidia, either $S s-7$ or $S s-12$. Tissues were removed 14 days later, and liver sections were prepared, stained with $\mathrm{H}$ and $\mathrm{E}$ and viewed microscopically. Swiss mice inoculated with $S s-12$ conidia had intact liver architecture with numerous small, focal mononuclear cell infiltrates in the periportal spaces (Fig. 4). Swiss mice that were inoculated with $S s-7$ conidia had a greater infiltration of mononuclear cells. The infiltrate in these mice was of periportal space origin (Fig. 4). When compared with mice inoculated with $S$. schenckii cultured for 12 days, the infiltrates of mice inoculated with Ss-7 conidia contained more mononuclear cells and were more numerous, with the appearance of granulomas. Bile ducts were dilated. Sinusoids in the parenchyma and central veins were visibly distended, suggesting liver congestion. Numerous areas of hepatocyte necrosis were apparent, but normal hepatocytes were visible. Structural organisation of hepatocytes into 

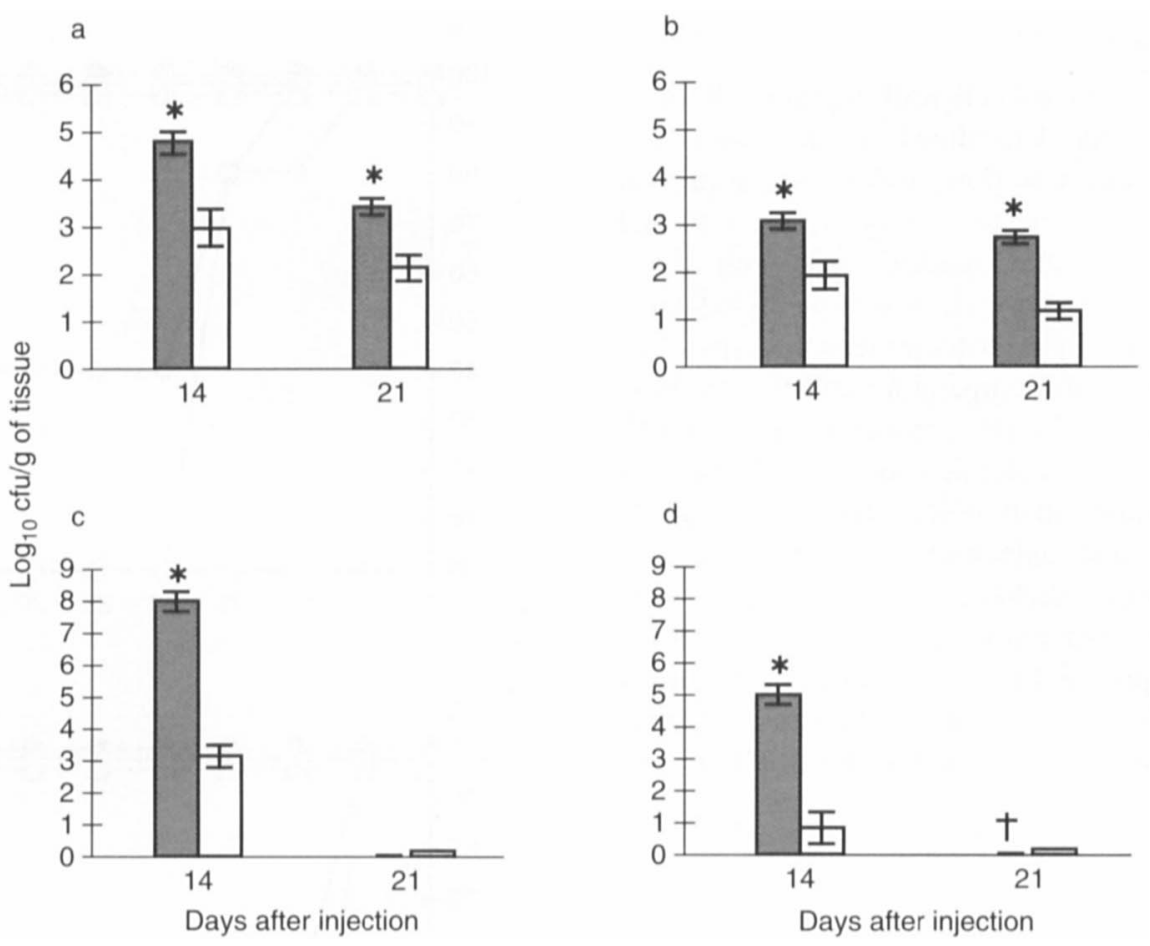

Fig. 2. Liver and spleen cfu for Swiss $(\mathbf{a}, \mathbf{b})$ or BALB/c (c, d) mice inoculated i.v. with $5 \times 10^{6}$ S. schenckii conidia. The conidia were cultured in SDB for 7 days $(\square)$ or 12 days $(\square)$. Control animals were inoculated with PBS and no colonies were detected. Each bar represents the mean (SD) of 4-8 animals. ${ }^{*}$ Statistically significant $(p<0.05)$. $\dagger$ Indicates that all animals were dead at that particular time. The $95 \%$ confidence intervals were distinct to each group compared statistically.

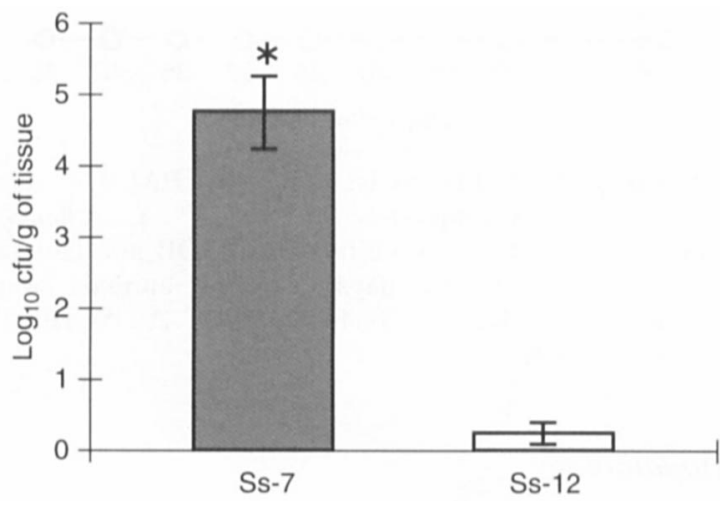

Fig. 3. Determination of $\mathrm{cfu}$ in the lungs of Swiss mice inoculated i.v. with $5 \times 10^{6} \mathrm{~S}$. schenckii conidia cultured for either 7 or 12 days, 14 days after infection. Control animals were inoculated with PBS. Each bar represents the mean $(\mathrm{n}=8)$ and SD. *Statistically significant $(\mathrm{p}<0.001)$. The $95 \%$ confidence intervals were distinct to each group compared statistically.

cords of cells was seriously distorted. BALB/c mice inoculated with $S s-12$ conidia had a massive infiltration of mononuclear cells that was not limited to periportal spaces (Fig. 5). Large granulomas were observed spreading through the parenchyma, including central veins and periportal spaces. Blood sinusoids in the parenchyma were obstructed due to liver congestion. Liver architecture was distorted, but identifiable. In BALB/c mice that were inoculated with $S s-7$ conidia, the whole liver was infiltrated by mononuclear cells (Fig. 5). The normal appearance of liver parenchyma was disrupted. Small numbers of remaining hepatocytes had a necrotic appearance with glassy, bluish, cytoplasm and the nuclei were disappearing.

\section{Agglutination tests}

Sera from mice (either BALB/c or Swiss) injected with $S s-7$ or $S s-12$ conidia were collected $14,21,28$, 35 and 42 days after fungal injection and analysed for reactivity with homologous or heterologous conidia (Fig. 6). On the 14th day, a high titre of agglutinating antibodies was observed in the sera of mice infected with $S s-7$. The titre was maintained through the 42 nd day after infection with similar reactivity for both $S s-7$ and $S s-12$ conidia. In contrast, the agglutination reaction for sera of mice infected with $S s-12$ showed low antibody titres until the 28th day after infection. On the 35 th and 42th days after infection, these sera showed significant differences $(p<0.05)$ in reactivity for homologous $(S s-12)$ and heterologous $(S s-7)$ conidia, independently of mouse strain (Fig. 6a and b).

\section{Cell-wall composition}

Cell-wall extracts from each type of conidia $(4,7,10$ and 12 days in culture) were obtained after autoclaving the cells in $0.02 \mathrm{M}$ citrate buffer and ethanol precipitation. Samples of each cell-wall extract were methanolysed, and the methyl-glycosides were silylated and analysed by GLC. Table 1 shows the molar ratios for sugars identified in each cell-wall extract. The main 

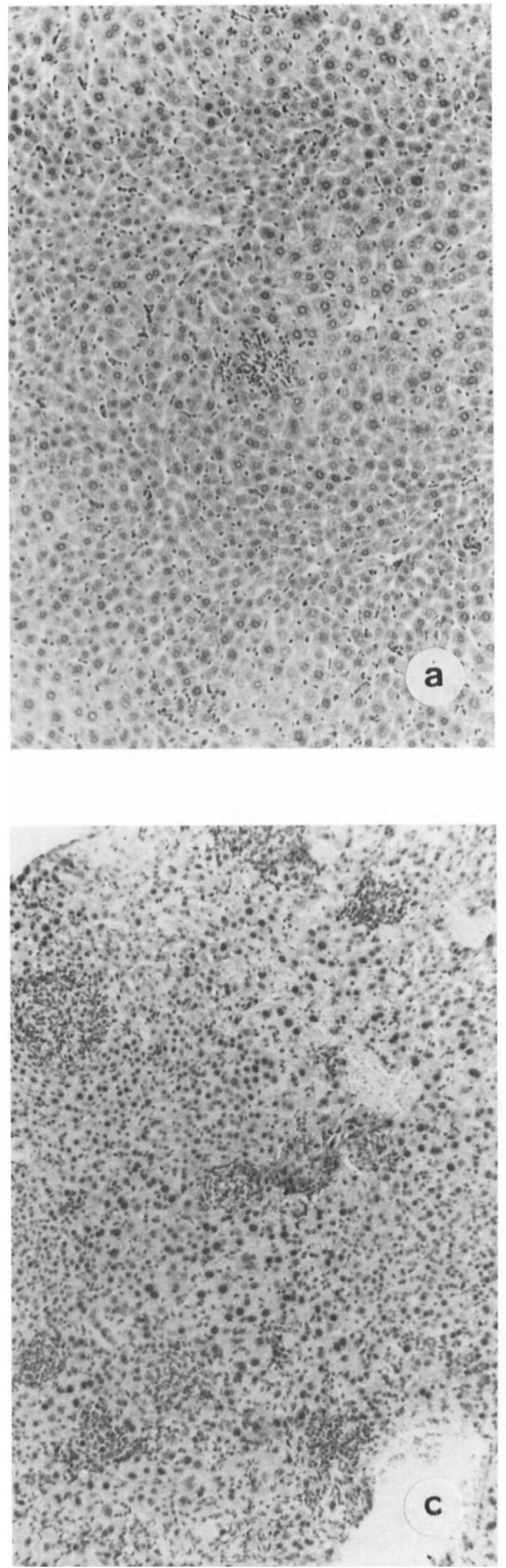
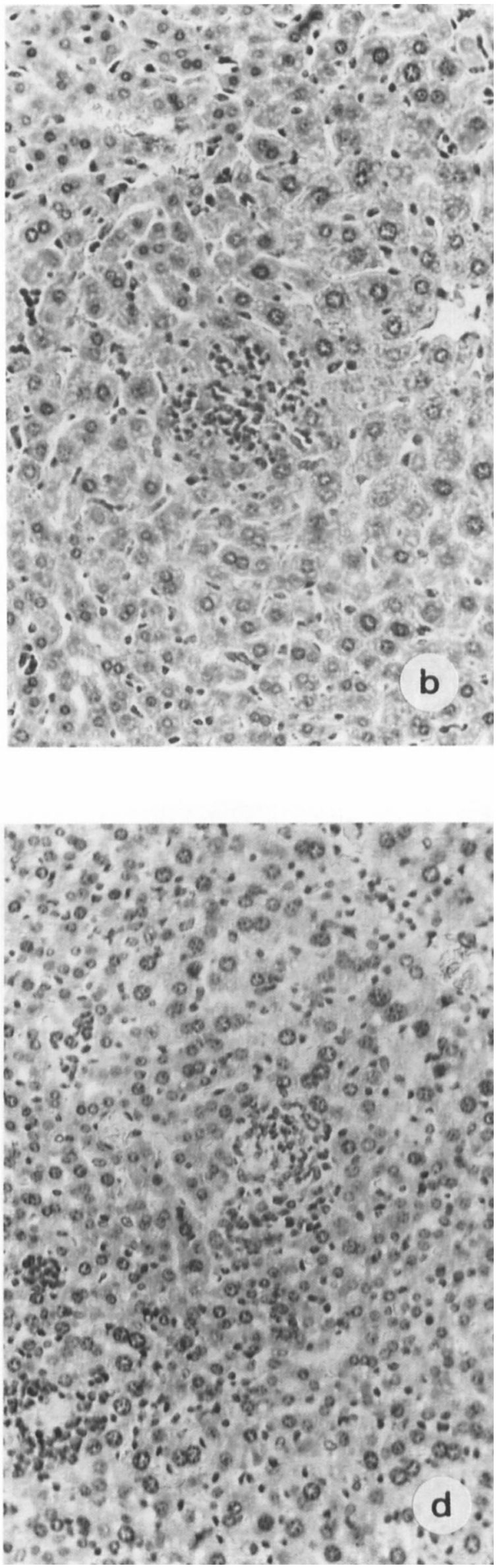

Fig. 4. Haematoxylin and eosin staining of sections of liver derived from Swiss mice given $S$. schenckii that had been

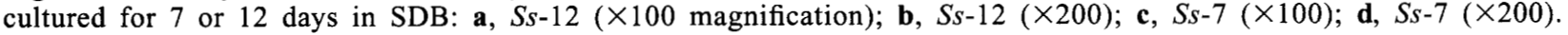



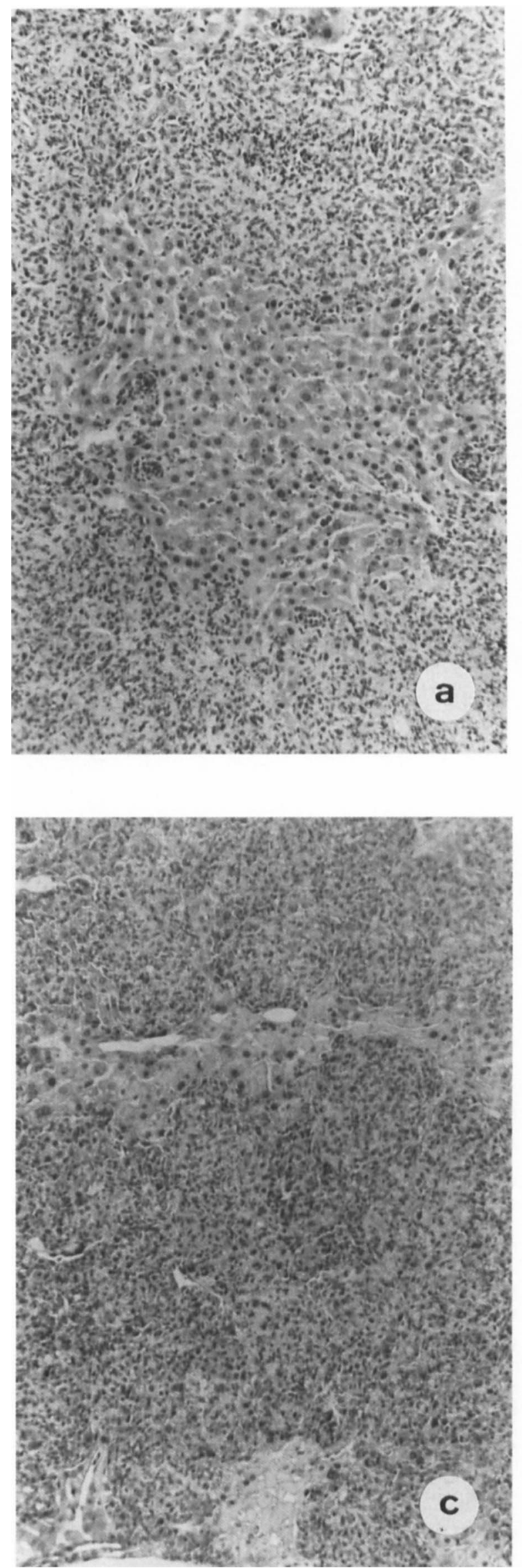
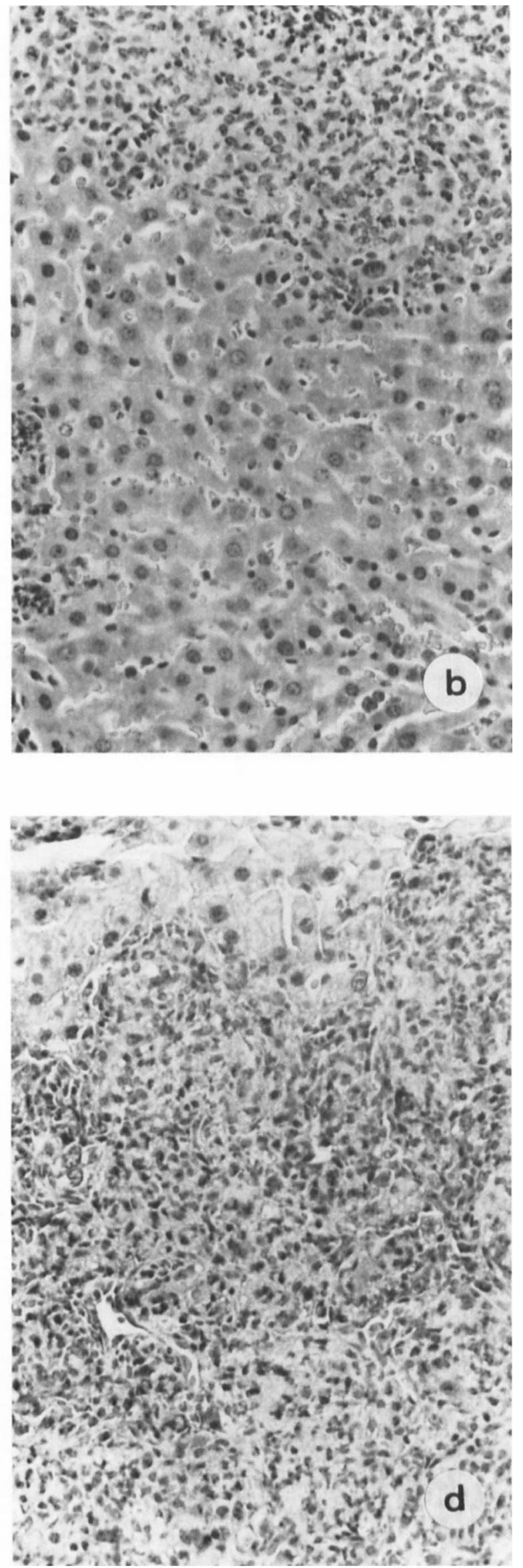

Fig. 5. Haematoxylin and eosin staining of sections of liver derived from BALB/c mice given $S$. schenckii that had been cultured for 7 or 12 days in SDB: a, Ss-12 ( $\times 100$ magnification); b, Ss-12 $(\times 200)$; c, Ss-7 $(\times 100)$; d, Ss-7 $(\times 200)$. 


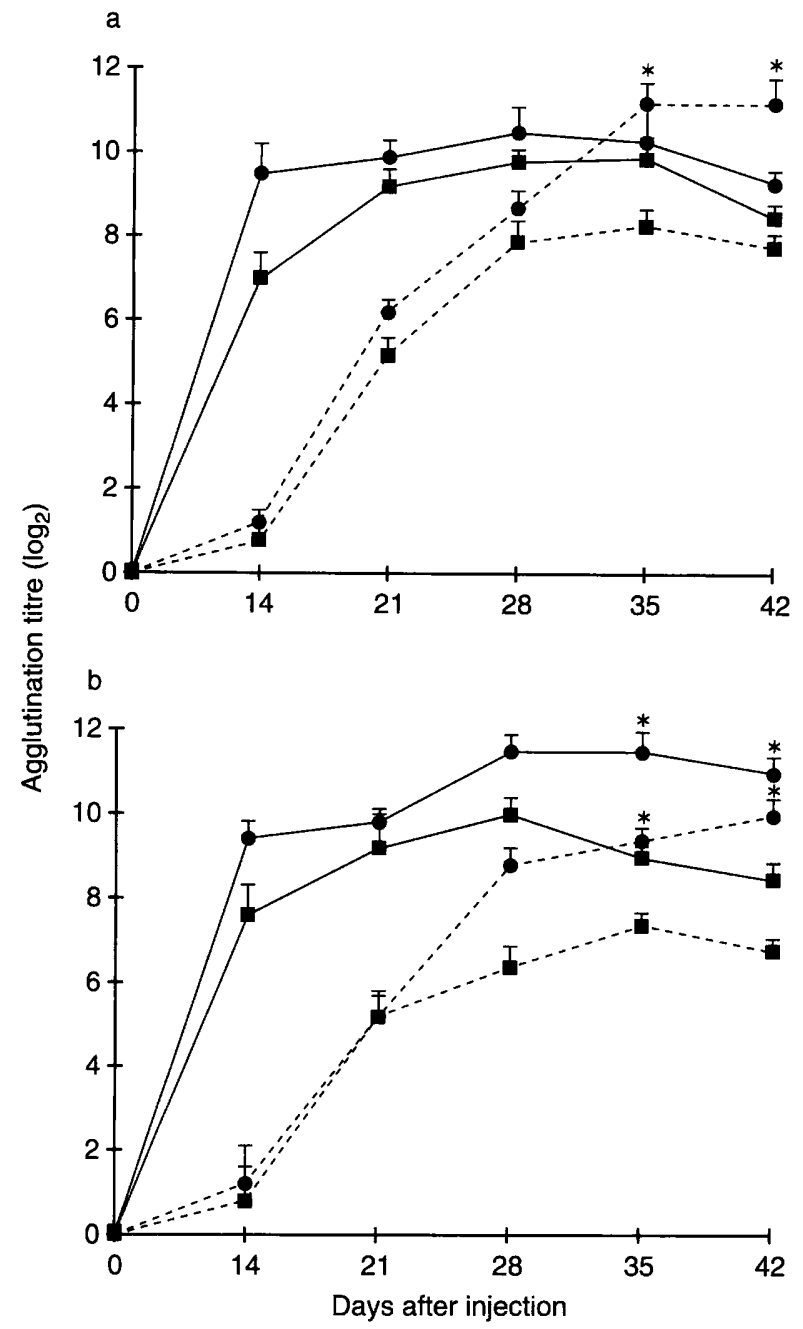

Fig. 6. Agglutination reaction of sera from (a) BALB/c and (b) Swiss mice infected with $S_{s-7}(-)$ or $S s-12$ (- - ) conidia of $S$. schenckii. Sera were collected on days $0,14,21,28,35$ and 42 and probed with the homologous and heterologous conidia: $S s-7$ (囟; $S s-12$ $(\bullet)$. Control groups were negative for agglutination reaction. The results represent the media and SD of five mice. *Significant statistical differences between homologous and heterologous reactions $(p<0.05)$.

Table 1. Sugar composition of crude cell-wall extracts of $S$. schenckii conidia cultivated for $4,7,10$ or 12 days in Sabouraud's dextrose broth

\begin{tabular}{lcccc}
\hline & \multicolumn{4}{c}{ Molar ratios* } \\
\cline { 2 - 5 } Conidia & Rha & Man & Gal & Glc \\
\hline$S s-4$ & 1.7 & 1.0 & ND & ND \\
$S s-7$ & 1.5 & 1.0 & ND & ND \\
$S s-10$ & 1.1 & 1.0 & ND & ND \\
$S s-12$ & 1.0 & 1.7 & 0.3 & 0.3
\end{tabular}

Rha, rhamnose; Man, mannose; Gal, galactose; Glc, glucose; ND, not detected.

* Molar ratios were determined by GLC analysis as described in Materials and methods.

sugars identified for all extracts were rhamnose and mannose, but the molar ratios between these two sugars changed significantly as the culture time increased. The rhamnose content was high for the cell-wall extracts of S. schenckii conidia cultured for 4 or 7 days in SDB.
An increase in the mannose content was observed in the cell-wall extract of $S$. schenckii conidia cultivated for 12 days. Traces of galactose and glucose were also identified in the $S s-12$ cell wall extract.

\section{Discussion}

BALB/c and Swiss mice were inoculated i.v. with conidia of $S$. schenckii that had been cultured for 4,7 , 10 or 12 days in SDB. The animals inoculated with conidia from the $\log$ phase of culture $(S s-4$ and $S s-7)$ developed an acute systemic disease characterised by high mortality, whereas animals inoculated with $S s-10$ or Ss-12 did not (Fig. 1); in these latter two groups, a less severe disease was observed. The virulence of the cultured conidia seemed to parallel conidial cell-wall sugar composition (Table 1). The more virulent conidia ( $S s-4$ and $S s-7$ ) had a higher rhamnose content than the less virulent conidia ( $S s-10$ and $S s-12)$. Differences in cell-wall composition have been shown to influence the pathogenic process of other medically important fungi such as Candida albicans [17] and Cryptococcus neoformans [18]. However, those studies were based on comparison either between virulent and avirulent strains [17] or between different fungal serotypes [19]. To our knowledge, no other evidence exists that suggests that cell-wall composition affects pathogenesis of a single fungal strain. The variation in the rhamnose:mannose molar ratio indicates differences in the expression of cell-surface glycoconjugates. Rhamnose residues on peptido-polysaccharides of S. schenckii are known to be the main antigenic epitopes present on the fungal cell surface $[14,20]$. Although a clear correlation between pathogenesis and cell-wall sugar composition was observed, the hypothesis that other factors or cell-wall components may also influence the course of the disease was not discarded. The evidence that the expression of cell-surface components varied between $S s-7$ and $S s-12$ was corroborated by the differing kinetics of agglutinating antibodies in sera of mice inoculated with either of these forms of conidia (Fig. 6). The titre of antibody reactive with $S s-7$, between the 14th and the 28th day after infection was significantly higher for sera of $S s$-12-infected mice, either against the homologous or heterologous conidia (Fig. 6). The difference in recognition pattern for $\mathrm{Ss}_{\mathrm{S}} \mathrm{7}$ and $S s-12$ conidia by sera of $S s-12$-infected mice suggested a variation in cell-surface antigenicity between these two forms of conidia. The peptidorhamnomannan that had been isolated from the cell wall of the yeast phase of $S$. schenckii was strongly reactive with sera from patients with sporotrichosis [21]. The main antigenic determinants present on peptido-rhamnomannan were related to the rhamnose terminal non-reducing end units $[14,20]$. It has been shown previously that the cell-wall rhamnomannans of the yeast and conidia of $S$. schenckii are structurally similar, with differences observed only with mycelial polysaccharides [22]. The role of these cell surface 
polymers in the modulation of the host immune response is not completely understood and is under investigation. It is well known that the outer cell-wall layer of the yeast form and conidia of $S$. schenckii is released into culture media [1]. The rhamnose:mannose composition of the sporotrichin antigen, isolated from culture filtrates of $S$. schenckii cultivated for different periods of time varied significantly [13]. The rhamnose content for the sporotrichin antigen rises according to culture time and the presence of this sugar has a direct correlation with the cutaneous delayed hypersensitivity reaction [13]. This observation suggests that the decrease in the rhamnose content for $S s-10$ and $S s-12$ conidia may be due, at least in part, to the loss of cellwall peptido-rhamnomannans into the culture medium. Ss-7 conidia showed a rhamnose:mannose molar ratio of 1.5:1.0 and mice inoculated with these conidia developed an acute disease with cfu in the lungs, liver and spleen (Figs. 2 and 3), when compared with the group of mice inoculated with $\mathrm{Ss}-12$ conidia (rhamnose:mannose molar ratio $1.0: 1.7$ ).

In the development of this experimental model, i.v. injection into the retro-orbital plexus of mice was used because the recovery of cfu from a number of different organs was more reproducible than that observed for either intraperitoneal or i.v. injection via the tail vein. The number of cfu found in the lungs of Swiss mice inoculated with $\mathrm{Ss}-7$ showed that these conidia were more virulent then $S s-12$ (Fig. 2). There was a clear correlation between the susceptibility of these mice to infection with $S$. schenckii and the recoverable number of fungi from their organs. With regard to human disease, it is possible that pulmonary sporotrichosis could be acquired by inhalation of conidia [3]. However, the route of inoculation used in this study does result in rapid recovery of the fungus from the lungs and the model does permit the analysis of different forms of conidia for their relative virulence.

The experimental model also produced revealing histopathology (Figs 4 and 5). BALB/c mice were more susceptible to the fungus than Swiss mice. The recoverable numbers of fungal cfu were greater in the organs of BALB/c mice than in the organs of infected Swiss mice. All BALB/c mice succumbed to infections when inoculated with $S$. schenckii cultured for 7 days, whereas $40 \%$ of Swiss mice survived such a challenge. In these groups of mice, the numbers of cfu were significantly higher in the BALB/c mice than in the Swiss mice (Fig. 2), although the splenomegaly determined by the splenic index was almost the same (data not shown). In $\mathrm{BALB} / \mathrm{c}$ mice that were inoculated with $S s-7$, the whole liver was infiltrated by mononuclear cells, with the normal appearance of the parenchyma fully disrupted. The numbers of hepatocytes were markedly reduced and many of those hepatocytes were either necrotic or pyknotic. Swiss mice that were inoculated with $S s-7$ conidia had less mononuclear cell infiltrate. The infiltrates had the appearance of granulomas and numerous areas of hepatocyte necrosis were apparent. In contrast to this, Swiss mice inoculated with Ss-12 conidia had relatively normal liver architecture and the mononuclear cell infiltrate was minimal. BALB/c mice inoculated with $S s-12$ had a massive infiltration of mononuclear cells. Large granulomas were observed spreading through the parenchyma. The histopathological sections used for these analyses were collected 14 days after infection of the animals. This time period was selected on the basis of the differential susceptibility of the animals to the fungus and the survival of the animals at this time period. The histopathology of the tissues derived 14 days after infection clearly showed that $S$. schenckii cultured for 7 days produced significantly more liver pathology than did $S$. schenckii cultured for 12 days.

These results suggest that differences in the cell-wall composition, as well as the nature of the mammalian host, may influence the outcome of infection with $S$. schenckii. The variation in the clinical presentation of sporotrichosis could have, to some extent, a correlation with the ambient conditions of the primary inoculum, which may determine the differences observed.

We thank Heclair R. P. Filho and Orlando A. Filho for their excellent technical support and to Dr Antonio C. da Silva. We also thank Drs José Osvaldo Previato and Lucia Mendonça-Previato for the use of their GLC system. Expert histological analysis by Joanna Goral and histological preparation by Mary K. Olson are gratefully acknowledged. This work was supported by CAPES, CNPq, FAPERJ and in part by USPHS AI-31127 and by the Cancer Federation.

\section{References}

1. Travassos LR. 'Sporothrix schenckii'. In: Szaniszlo PJ (ed) Fungal dimorphism, with emphasis on fungi pathogenic for humans. New York, Plenum Press. 1985: 121-163.

2. Castrejón OV, Robles M, Zubieta Arroyo OE. Fatal fungaemia due to Sporothrix schenckii. Mycoses 1995; 38: 373-376.

3. Farley ML, Fagan MF, Mabry LC, Wallace RJ. Presentation of Sporothrix schenckii in pulmonary cytology specimens. Acta Cytol 1991; 35: 389-395.

4. Heller HM, Fuhrer J. Disseminated sporotrichosis in patients with AIDS: case report and review of the literature. AIDS 1991; 5: 1243-1246.

5. Padhye AA, Kaufman L, Durry E et al. Fatal pulmonary sporotrichosis caused by Sporothrix schenckii var. luriei in India. J Clin Microbiol 1992; 30: 2492-2494.

6. Charoenvit Y, Taylor RL. Experimental sporotrichosis in Syrian hamsters. Infect Immun 1979; 23: 366-372.

7. Dixon DM, Duncan RA, Hurd NJ. Use of mouse model to evaluate clinical and environmental isolates of Sporothrix sp. from the largest U.S. epidemic of sporotrichosis. $J$ Clin Microbiol 1992; 30: 951-954.

8. Dickerson CL, Taylor RL, Drutz DJ. Susceptibility of congenitally athymic (nude) mice to sporotrichosis. Infect Immun 1983; 40: 417-420.

9. Restrepo-Gutierrez S, Arango-Arteaga M, Uribe-Jaramillo F, Zuluaga-Cadena AI, Restrepo-Moreno A. Course of experimental murine infection induced by Sporothrix schenckii conidia according to depth of inoculation. J Med Vet Mycol 1993; 31: 411-420.

10. Miyaji M, Nishimura K. Defensive role of granuloma against 
Sporothrix schenckii infection. Mycopathologia 1982; 80: 117124.

11. Garrison RG, Boyd KS, Mariat F. Ultrastructural studies of the mycelium-to-yeast transformation of Sporothrix schenckii. $J$ Bacteriol 1975; 124: 959-968.

12. Travassos LR. Antigenic structures of Sporothrix schenckii. In: Kurstak E (ed) Immunology of fungal diseases. New York, Marcel Dekker. 1989: 193-221.

13. Takata M, Ishizaki $\mathrm{H}$. Correlation among culture times, sugar composition and biological activities of Sporothrix schenckii antigens. Mycophatologia 1983; 84: 31-39.

14. Lopes Alves L, Travassos LR, Previato JO, Mendonça-Previato L. Novel antigenic determinants from peptidorhamnomannans of Sporothrix schenckii. Glycobiology 1994; 4: 281-288.

15. Lopes Alves LM, Mendonça-Previato L, Fournet B, Degand P, Previato JO. O-glycosidically linked oligosaccharides from peptidorhamnomannans of Sporothrix schenckii. Glycoconjugate $J$ 1992; 9: 75-81.

16. Lloyd KO. Isolation, characterization, and partial structure of peptidogalactomannans from the yeast form of Cladosporium werneckii. Biochemistry 1970; 9: 3446-3453.
17. Mencacci A, Torosantucci A, Spaccapelo R, Romani L, Bistoni F, Cassone A. A mannoprotein constituent of Candida albicans that elicits different levels of delayed-type hypersensitivity, cytokine production, and anticandidal protection in mice. Infect Immun 1994; 62: 5353-5360.

18. Kozel TR. Virulence factors of Cryptococcus neoformans. Trends Microbiol 1995; 3: 295-299.

19. Irokanulo EAO, Akueshi CO. Virulence of Cryptococcus neoformans serotypes A, B, C and D for four mouse strains. J Med Microbiol 1995; 43: 289-293.

20. Lloyd KO, Travassos LR. Immunochemical studies on Lrhamno-D-mannans of Sporothrix schenckii and related fungi by use of rabbit and human antisera. Carbohydr Res 1975; 40: 89-97.

21. Lloyd $\mathrm{KO}$, Bitoon MA. Isolation and purification of a peptidorhamnomannan from the yeast form of Sporothrix schenckii. Structural and immunochemical studies. J Immunol 1971; 107: 663-671.

22. Travassos LR, Mendonça-Previato L. Synthesis of monorhamnosyl L-rhamno-D-mannans by conidia of Sporothrix schenckii. Infect Immun 1978; 19: 1-4. 